ORIGINAL ARTICLE

\title{
HIV testing attitudes, AIDS stigma, and voluntary HIV counselling and testing in a black township in Cape Town, South Africa
}

\author{
S C Kalichman, L C Simbayi
}

Sex Transm Infect 2003;79:442-447

See end of article for authors' affiliations .....................

Correspondence to: Seth C Kalichman, Department of Psychology, 406 Babbidge Road, University of Connecticut, Storrs, CT 06269, USA; seth.k@uconn.edu

Accepted for publication 10 June 2003
Objectives: A cornerstone of HIV prevention in South Africa is voluntary HIV antibody counselling and testing (VCT), but only one in five South Africans aware of VCT have been tested. This study examined the relation between HIV testing history, attitudes towards testing, and AIDS stigmas.

Methods: Men $(n=224)$ and women $(n=276)$ living in a black township in Cape Town completed venue intercept surveys; $98 \%$ were black, $74 \%$ age 35 or younger.

Results: $47 \%$ of participants had been tested for HIV. Risks for exposure to HIV were high and comparable among people tested and not tested. Comparisons on attitudes toward VCT, controlling for demographics and survey venue, showed that individuals who had not been tested for HIV and those tested but who did not know their results held significantly more negative testing attitudes than individuals who were tested, particularly people who knew their test results. Compared to people who had been tested, individuals who were not tested for HIV demonstrated significantly greater AIDS related stigmas; ascribing greater shame, guilt, and social disapproval to people living with HIV. Knowing test results among those tested was not related to stigmatising beliefs.

Conclusions: Efforts to promote VCT in South Africa require education about the benefits of testing and, perhaps more important, reductions in stigmatising attitudes towards people living with AIDS. Structural and social marketing interventions that aim to reduce AIDS stigmas will probably decrease resistance to seeking VCT.
S outh Africa is in the midst of a catastrophic AIDS epidemic, with between $11 \%$ and $20 \%$ of South African adults HIV infected, 420000 children orphaned by AIDS, and 1500 new HIV infections each day. ${ }^{12}$ To help slow the spread of HIV, the South African government and international aid organisations are investing significant prevention resources in voluntary counselling and testing (VCT). The South African government has established more than 450 VCT centres with more than 800 counsellors around the country. ${ }^{1}$ Research conducted in developed and developing countries has shown that VCT can reduce high risk sexual practices and can decrease rates of sexually transmitted infections. ${ }^{3}{ }^{4}$ In addition, VCT is necessary for directing HIV infected people to antiretroviral therapy, which is becoming increasingly available in South Africa.

Only a fraction of South Africans at risk for HIV have undergone VCT. Although most South Africans are aware that VCT services are available, only one in five people in South Africa who know about VCT have been tested for HIV. ${ }^{1}$ Among the reasons that South Africans may not seek HIV testing are negative perceptions of testing services. In studies of men who have sex with men ${ }^{5}$ and adults receiving sexually transmitted disease clinic services in the United States, ${ }^{6}$ individuals who view more positive and fewer adverse outcomes from HIV testing are more likely to have been tested. However, the relations between testing attitudes and seeking VCT in South Africa have thus far received limited attention.

AIDS related stigmas are another factor that probably influence seeking VCT in South Africa. Stigmatising beliefs about AIDS and their associated fears of discrimination can influence decisions to seek HIV testing and HIV treatment services. ${ }^{78}$ In a study conducted in the United States, Stall et $a l^{9}$ reported that two out of three men who have sex with men who were unaware of their HIV status indicated that AIDS related stigmas were an important factor in their testing decisions. More recently, Herek et al $^{10}$ found that $38 \%$ of a US national sample of adults stated that they would be very concerned about stigma if they tested HIV positive, and $44 \%$ of people who expressed this concern indicated that stigma influences their testing decisions. In South Africa, AIDS related stigmas are also socially and culturally pervasive. ${ }^{11}$ In a South African national survey, $26 \%$ of respondents would not be willing to share a meal with a person living with AIDS, 18\% were unwilling to sleep in the same room with someone with AIDS, and 6\% would not talk to a person they knew to have AIDS. ${ }^{1}$ Stigmas may therefore pose considerable barriers to seeking VCT in South Africa. To our knowledge, the degree to which AIDS stigmatising beliefs are related to HIV testing in South Africa has not been reported.

This study examined social and cognitive factors that may influence health decisions in relation to HIV testing history in South Africa. A multivenue community sampling strategy was used to obtain a cross sectional sample of South Africans residing in a black township in Cape Town. The study focused on comparing individuals who had been tested for HIV with individuals who had not yet been tested on measures of (a) HIV prevention knowledge, (b) HIV testing attitudes, and (c) AIDS stigmas. Comparisons were also made between people who knew their HIV test results and individuals who were tested but did not know their results. The selection of social cognitive factors related to testing examined in this study was guided by the information-motivation-behavioural skills model of health behaviour, ${ }^{12}$ which posits that information (knowledge) and motivation (attitudes and beliefs) are critical in influencing HIV testing decisions. Accordingly, misinformation about AIDS, HIV testing attitudes, and AIDS 
stigmatising beliefs represent potential barriers to seeking HIV testing ${ }^{10}{ }^{13}$ and were the focus of the current study.

\section{METHODS}

\section{Participants and setting}

Participants were 224 men and 276 women living in a black township in Cape Town, South Africa. The median age range was 21 to 25 years, $67 \%$ of participants were married, 52\% completed high school, and 61\% were not employed (see table 1). Participants were recruited from multiple venues in a township located within 50 miles of Cape Town. The Western Cape has an estimated HIV prevalence of $10.7 \%$ and the majority of HIV infections in the Western Cape occur in townships. ${ }^{1}$ The township that participated in the current study has a population of over 100000 , with a median monthly household income of 384 South African rands (\$US42) and a median of five people per household.

\section{Measures}

Participants completed anonymous self administered surveys at multiple community venues. Surveys were administered in English and Xhosa. Measures included demographic characteristics, HIV testing history, HIV risk behaviour history, HIV prevention knowledge, HIV testing attitudes, and AIDS stigmas.

\section{Demographic characteristics}

Participants were asked their sex, age, years of education completed, employment status, marital status, and race.

\section{HIV testing history}

The survey included questions concerning history of HIV antibody testing. These measures were used to classify participants into groups based on whether they had been tested for HIV. Participants who reported having been tested for HIV indicated the results of their most recent test as positive, negative, or that they did not know the results.
Participants who had been tested also reported the number of times they had ever been tested for HIV.

\section{HIV risk behaviour history}

To assess HIV risk history, participants indicated the number of sex partners they had in the previous 3 months, whether they had ever exchanged sex for money or other survival needs, received a sexually transmitted infection (STI) diagnosis, had a genital ulcer, injected drugs, or had an injection drug using sex partner, and whether they had ever used a condom. All responses were dichotomous indicating the occurrence or non-occurrence of each risk factor.

\section{HIV prevention knowledge}

A 12 item test was used to assess HIV risk and prevention related knowledge. Items were adapted from a measure reported by Carey and Schroder ${ }^{14}$ and reflected information about HIV transmission, condom use, and AIDS related knowledge and were responded to as yes, no, or don't know (see table 2 for knowledge items). The AIDS knowledge test was scored for the number of correct responses, with don't know responses scored incorrect. The AIDS knowledge test was internally consistent, alpha $=0.70$.

\section{HIV testing attitudes}

Participants responded to five HIV testing attitude items. The items were adapted from previous research on HIV testing and testing attitudes. ${ }^{6}$ Two items reflected positive outcomes from testing, two assessed adverse outcomes, and one item reflected HIV testing avoidance (see table 3). Items were responded to dichotomously, as either agree or disagree.

\section{AIDS stigmas}

Thirteen AIDS stigma items were adapted from previous research and developed for use in South Africa. ${ }^{15}$ The AIDS stigma items reflected negative beliefs about people living with AIDS (for example, dirty, cursed, untrustworthy),

Table 1 Demographic characteristics and HIV risk behaviour history among participants from a black township in Cape Town who have and have not been tested for HIV

\begin{tabular}{|c|c|c|c|c|c|c|c|c|}
\hline & \multicolumn{4}{|l|}{ Tested } & \multirow{3}{*}{\multicolumn{2}{|c|}{$\begin{array}{l}\text { Not tested for HIV } \\
(n=266)\end{array}$}} & \multirow{3}{*}{\multicolumn{2}{|c|}{ Adjusted }} \\
\hline & \multicolumn{4}{|l|}{ Results } & & & & \\
\hline & \multicolumn{2}{|c|}{ Known $(n=117)$} & \multicolumn{2}{|c|}{ Unknown ( $n=86$ ) } & & & & \\
\hline & No & $\%$ & No & $\%$ & No & $\%$ & $\mathrm{OR}^{*}$ & OR† \\
\hline \multicolumn{9}{|l|}{ Demographic characteristics } \\
\hline Male & 58 & 52 & 41 & 47 & 110 & 41 & 1.2 & 1.4 \\
\hline Female & 54 & 48 & 46 & 53 & 156 & 59 & & \\
\hline \multirow{4}{*}{$\begin{array}{l}25 \text { and younger } \\
26 \text { to } 35 \\
36 \text { to } 45 \\
46 \text { and over }\end{array}$} & 51 & 45 & 30 & 35 & 137 & 52 & 0.9 & 1.1 \\
\hline & 39 & 35 & 38 & 45 & 53 & 20 & & \\
\hline & 18 & 16 & 12 & 14 & 48 & 18 & & \\
\hline & 4 & 4 & 5 & 6 & 23 & 10 & & \\
\hline \multirow{2}{*}{$\begin{array}{ll}\text { Race } & \text { African } \\
\text { Other }\end{array}$} & 110 & 99 & 82 & 94 & 264 & 99 & 0.5 & 3.5 \\
\hline & 1 & 1 & 5 & 6 & 2 & 1 & & \\
\hline Years of education (mean, SD) & 8.6 & 1.2 & 8.5 & 1.2 & 8.2 & 1.3 & $0.8^{a}$ & 0.9 \\
\hline Employed & 50 & 46 & 37 & 43 & 91 & 35 & 1.4 & 1.5 \\
\hline Married & 37 & 33 & 37 & 43 & 81 & 31 & 1.0 & 0.6 \\
\hline \multicolumn{9}{|l|}{ Risk history factors } \\
\hline Two or more sex partnersł & 42 & 38 & 46 & 53 & 107 & 40 & 1.0 & 1.1 \\
\hline Received money, food for sex & 7 & 6 & 17 & 20 & 33 & 13 & 0.8 & $0.2^{a}$ \\
\hline Given money, food for sex & 9 & 8 & 13 & 15 & 22 & 8 & 1.2 & $0.4^{\mathrm{b}}$ \\
\hline Has been diagnosed with an STD & 45 & 40 & 40 & 48 & 74 & 28 & $1.7^{a}$ & 0.8 \\
\hline Genital ulcer & 17 & 15 & 11 & 13 & 33 & 13 & 1.0 & 1.1 \\
\hline Has injected drugs & 1 & 1 & 3 & 4 & 18 & 7 & $0.3^{b}$ & 0.2 \\
\hline Has had an injection drug using sex partner & 9 & 8 & 6 & 7 & 31 & 12 & 0.6 & 1.0 \\
\hline Never used a condom & 8 & 7 & 4 & 5 & 70 & 26 & $5.6^{\mathrm{a}}$ & 0.6 \\
\hline
\end{tabular}




\begin{tabular}{|c|c|c|c|c|c|c|}
\hline & \multicolumn{4}{|c|}{ Tested } & \multirow{3}{*}{\multicolumn{2}{|c|}{$\begin{array}{l}\text { Not tested for HIV } \\
(n=266)\end{array}$}} \\
\hline & \multicolumn{4}{|c|}{ Results } & & \\
\hline & \multicolumn{2}{|c|}{$\begin{array}{l}\text { Known } \\
(n=117)\end{array}$} & \multicolumn{2}{|c|}{ Unknown $(n=86)$} & & \\
\hline & No & $\%$ & No & $\%$ & No & $\%$ \\
\hline Is AIDS spread by kissing? (No)* & 6 & 5 & 7 & 8 & 26 & 10 \\
\hline $\begin{array}{l}\text { Can a person get AIDS by sharing kitchens and } \\
\text { bathrooms with someone with AIDS? (No) }\end{array}$ & 2 & 2 & 4 & 5 & 21 & 8 \\
\hline Can men give AIDS to women? (Yes) & 7 & 6 & 2 & 2 & 26 & 10 \\
\hline Can women give AIDS to men? (Yes) & 8 & 7 & 3 & 4 & 21 & 8 \\
\hline $\begin{array}{l}\text { Must a person have many different partners } \\
\text { to get AIDS? (No) }\end{array}$ & 30 & 27 & 15 & 18 & 81 & 31 \\
\hline $\begin{array}{l}\text { Can you get AIDS by touching someone } \\
\text { with AIDS? (No) }\end{array}$ & 4 & 4 & 8 & 9 & 30 & 11 \\
\hline $\begin{array}{l}\text { Does washing after sex help protect against } \\
\text { AIDS? (No) }\end{array}$ & 29 & 26 & 17 & 20 & 67 & 25 \\
\hline $\begin{array}{l}\text { Is AIDS caused by spirits/supernatural forces? } \\
\text { (No) }\end{array}$ & 28 & 25 & 34 & 39 & 86 & 33 \\
\hline $\begin{array}{l}\text { Can a pregnant woman give AIDS to her baby? } \\
\text { (Yes) }\end{array}$ & 13 & 12 & 8 & 9 & 34 & 13 \\
\hline $\begin{array}{l}\text { Can a person get rid of AIDS by having sex } \\
\text { with a virgin? (No) }\end{array}$ & 11 & 10 & 10 & 11 & 39 & 15 \\
\hline Is HIV the virus that causes AIDS? (Yes) & 10 & 9 & 12 & 14 & 29 & 11 \\
\hline Is there a cure for AIDS? (No) & 26 & 23 & 27 & 31 & 59 & 22 \\
\hline Total knowledge score (mean, SD \% correct) & 85.7 & 15.2 & 84.5 & 17.7 & 82.3 & 17.6 \\
\hline
\end{tabular}

shamefulness of the behaviour of people with AIDS (for example, guilt, shame, weak), and the endorsement of social sanctions against people with HIV-AIDS (for example, should not work with children, restrictions on freedom, isolation). These items were also responded to dichotomously as either agree or disagree.

\section{Procedures}

Participants were approached while attending one of 12 venues within the township. Venues included a day hospital ( $9 \%$ of the sample), two health clinics representing $20 \%$ of participants, shops and vendors (11\%), four taxi areas (19\%), street junctions $(28 \%)$, and social congregating areas $(13 \%)$. These venues were selected because they represent all public access areas in the township. Participants were approached by a field worker and asked whether they would take a short time to answer an anonymous questionnaire. All potential participants present at the venue were approached to participate and $90 \%$ of people approached agreed to complete the survey. All people who agreed to complete the survey were able to self administer the measures with minimal assistance. Participants received 15 rand $(\$ 1.75)$ to compensate for their time and effort for participating.

\section{Data analyses}

Participants who responded to the item regarding whether they had ever been tested for HIV (97\%) were initially divided into two groups (a) individuals who had been tested for HIV and (b) individuals who had not been tested for HIV. Twelve participants (3\%) refused to answer the HIV testing history question and were omitted from analyses. Individuals who reported having tested HIV positive $(n=19)$ were also excluded. Comparisons of people who were tested with those who were not tested were conducted on demographic characteristics, HIV risk behaviour history, HIV prevention knowledge, HIV testing attitudes, and AIDS stigmas using multiple logistic regression analyses, adjusted for participant age, education, sex, and survey venue. These covariates were selected because of their potential associations with risk history and access to health care. In addition, participants who had been tested for HIV were grouped on the basis of knowing their HIV test results and compared on the same measures described above; 117 individuals who knew their test results compared with 86 who did not know their HIV test results. Adjusted odds ratios are reported with 95\% confidence intervals.

\section{RESULTS}

\section{HIV testing history}

Results showed that 222 (44\%) participants indicated that they had been tested for HIV, 266 (53\%) had not been tested, and $12(3 \%)$ refused to respond whether they had been tested for HIV. Most participants who were tested for HIV had been tested once $(33 \%)$, twice $(29 \%)$, or three times $(19 \%)$. Of people who had been tested, 117 (53\%) reported that they were HIV negative at their most recent test, 19 (9\%) were HIV positive, and $86(38 \%)$ did not learn the results of their HIV test.

Comparisons of people who had been tested and were not HIV positive $(n=203)$ with those who were not tested for HIV $(n=266)$ on demographic characteristics indicated that individuals who had been tested had significantly more years of education than people not tested, although the difference between means was less than one year of education (see table 1). No other significant differences in demographic characteristics were found between people who had been tested for HIV and people who had not been tested. Among participants who were tested there were no differences in demographic characteristics between individuals who knew their HIV test results and those who did not know their results.

\section{HIV risk behaviours}

Comparisons of individuals who had been tested for HIV and those not tested for HIV on risk behaviour history variables are shown in table 1. Risk factors for HIV were generally high and for the most part comparable between the two testing groups. Over $40 \%$ of both groups had two or more sex partners in the previous 3 months. More than $10 \%$ of participants had traded sex to meet survival needs, $35 \%$ 
Table 3 HV testing attitudes and AIDS stigmatising attitudes among participants from a black township in Cape Town who have and have not been tested for HIV

\begin{tabular}{|c|c|c|c|c|c|c|c|c|}
\hline & \multicolumn{4}{|c|}{ Tested } & \multirow{3}{*}{\multicolumn{2}{|c|}{$\begin{array}{l}\text { Not tested for HIV } \\
(n=266)\end{array}$}} & \multirow{3}{*}{\multicolumn{2}{|c|}{ Adjusted }} \\
\hline & \multicolumn{4}{|c|}{ Results } & & & & \\
\hline & \multicolumn{2}{|c|}{ Known $(n=117)$} & \multicolumn{2}{|c|}{ Unknown $(n=86)$} & & & & \\
\hline & No & $\%$ & No & $\%$ & No & $\%$ & $\mathrm{OR}^{*}$ & OR† \\
\hline \multicolumn{9}{|l|}{ HIV testing attitudes } \\
\hline Getting tested for HIV helps people feel better & 95 & 86 & 71 & 82 & 175 & 66 & $2.9^{a}$ & 1.5 \\
\hline Getting tested for HIV helps people from getting HIV & 89 & 90 & 58 & 67 & 150 & 57 & $2.2^{a}$ & $2.6^{\mathrm{a}}$ \\
\hline People in my life would leave me if I had HIV & 20 & 18 & 28 & 32 & 109 & 41 & $0.5^{\mathrm{a}}$ & $0.4^{\mathrm{a}}$ \\
\hline People who test HIV positive should hide it from others & rs11 & 10 & 23 & 27 & 91 & 35 & $0.4^{\mathrm{a}}$ & $0.3^{\mathrm{a}}$ \\
\hline I would rather not know if I have HIV & 31 & 28 & 40 & 46 & 126 & 48 & $0.5^{\mathrm{a}}$ & $0.4^{\mathrm{a}}$ \\
\hline \multicolumn{9}{|l|}{ AIDS stigmas } \\
\hline People who have AIDS are dirty & 4 & 4 & 2 & 2 & 27 & 10 & $0.3^{\mathrm{a}}$ & 1.6 \\
\hline People who have AIDS are cursed & 7 & 6 & 6 & 7 & 31 & 12 & 0.5 & 0.8 \\
\hline People who have AIDS cannot be trusted & 20 & 18 & 17 & 20 & 63 & 24 & 0.7 & 0.8 \\
\hline People who have AIDS are like everybody else & 92 & 83 & 73 & 87 & 204 & 77 & 1.6 & 0.8 \\
\hline People who have AIDS should be ashamed & 8 & 7 & 8 & 9 & 52 & 20 & $0.4^{\mathrm{a}}$ & 0.7 \\
\hline $\begin{array}{l}\text { People who have AIDS have nothing to feel guilty } \\
\text { about }\end{array}$ & 89 & 78 & 64 & 74 & 168 & 64 & $2.0^{\mathrm{a}}$ & 1.5 \\
\hline $\begin{array}{l}\text { Most people become HIV positive by being weak or } \\
\text { foolish }\end{array}$ & 18 & 16 & 17 & 20 & 57 & 22 & 0.8 & 0.6 \\
\hline $\begin{array}{l}\text { It is safe for people who have AIDS to work with } \\
\text { children }\end{array}$ & 76 & 68 & 58 & 67 & 134 & 52 & $1.9^{\mathrm{a}}$ & 1.1 \\
\hline $\begin{array}{l}\text { People who have AIDS must expect restrictions } \\
\text { on their freedom }\end{array}$ & 30 & 27 & 39 & 45 & 122 & 47 & 0.7 & 0.5 \\
\hline $\begin{array}{l}\text { A person with AIDS must have done something } \\
\text { wrong and deserves to be punished }\end{array}$ & 2 & 2 & 6 & 7 & 32 & 12 & $0.3^{\mathrm{a}}$ & 0.2 \\
\hline People who have HIV should be isolated & 6 & 5 & 5 & 6 & 22 & 7 & 0.8 & .08 \\
\hline $\begin{array}{l}\text { I do not want to be friends with someone who has } \\
\text { AIDS }\end{array}$ & 5 & 5 & 3 & 3 & 34 & 13 & $0.3^{a}$ & 1.0 \\
\hline $\begin{array}{l}\text { People who have AIDS should not be allowed } \\
\text { to work }\end{array}$ & 14 & 13 & 14 & 16 & 45 & 17 & 0.9 & 0.6 \\
\hline
\end{tabular}

*OR = odds ratios for comparisons of people tested for HIV to people not tested; $+\mathrm{OR}=$ odds ratios for comparisons of people who have been tested with known results to people tested with unknown results; All odds ratios adjusted for age, years education, sex, and survey venue; ${ }^{a} p<0.01 ;{ }^{b} p<0.05$.

had had an STI, and 13\% had a history of genital ulcers. Analyses showed that people who were not tested for HIV were more likely to have never used a condom and were more likely to have used injection drugs, both indicating potential higher risk among untested people. Participants who had been tested were, however, significantly more likely to have been diagnosed with an STI. Taken together, $69 \%$ of those who had been tested indicated at least one of seven HIV risk factors (excluding never having used a condom), as did 62\% of those who had not been tested, a non-significant difference. Among people who had been tested, those who did not know their test results were significantly more likely to have received and given money or food for sex, suggesting that people involved in sex trade were less likely to know their HIV test results.

\section{HIV-AIDS prevention knowledge}

Across all participants AIDS knowledge was generally high; mean score on the knowledge test was $83 \%$ correct for the sample (see table 2). However, there was evidence of important misinformation in the context of this relatively high knowledge base. Items that were most frequently answered incorrect were "Must a person have many different partners to get AIDS?" 26\%; "Is AIDS caused by spirits or supernatural forces?" 43\%; "Does washing after sex help protect against AIDS?" 24\%; and "Is there a cure for AIDS?" $24 \%$. Comparisons between individuals who had been and who had not been tested for HIV showed that groups did not differ significantly on HIV knowledge test scores, adjusted $\mathrm{OR}=0.49,95 \% \mathrm{CI}=0.15$ to 1.58 , and there were no significant group differences on any of the individual knowledge items. There were also no differences between people who knew their HIV test results and people who did not know their results in AIDS knowledge, adjusted $\mathrm{OR}=0.95,95 \% \mathrm{CI}=0.81$ to 1.1 .

\section{Attitudes toward HIV testing}

Comparisons between HIV testing history groups on attitudes towards HIV testing showed that participants who had not been tested held significantly more negative HIV testing attitudes than participants who had been tested after controlling for age, sex, education, and survey venue. Individuals who had not been tested for HIV were significantly less likely to view beneficial outcomes from testing, more likely to perceive adverse testing outcomes, and more likely to endorse test avoidance (see table 3).

Among people who had been tested, individuals who did not know their HIV test results demonstrated significantly more negative attitudes towards testing than those who knew their test results. These findings mirror the results of comparisons between people tested and not tested for HIV. Participants who did know their test results were less likely to endorse benefits and were more likely to endorse adverse outcomes from testing.

\section{AIDS stigmas}

Results showed that individuals who had not been tested for HIV held significantly greater AIDS related stigmas than individuals who had been tested. People who had not been tested were significantly more likely to agree that people with AIDS are dirty, should feel ashamed, and should feel guilty. Participants who were not tested were also more likely to believe that people with AIDS must have done something wrong to have AIDS and were more likely to endorse that they would rather not be friends with someone who has AIDS. Finally, individuals who had not been tested were significantly more likely than those who had been tested to 
agree that people with AIDS should not be allowed to work with children.

For people who had been tested, there were no significant differences between those who knew their results and those who did not know their test results on AIDS stigmatising beliefs.

\section{DISCUSSION}

Results showed that $53 \%$ of participants had not been tested for HIV and two out of three of those indicated at least one behavioural risk factor that places them at high risk for HIV infection. Risks for HIV were substantial among people who had not been tested, including $28 \%$ having been diagnosed with an STI and 13\% having a history of genital ulcers. Given that HIV prevalence rates in South Africa are highest among blacks living in townships and the surrounding informal settlements, especially among those with STIs and genital ulcer disease, a substantial number of the untested individuals in this study were probably infected with HIV.

More than one in three people who had been tested were not aware of their HIV test results. Although it is common for people to not return for their test results when they have to wait days for test result notification, ${ }^{16}$ this high rate of unknown test results is surprising because South Africa has instituted rapid testing with same day results. ${ }^{17}$ People who did not know their test results were more likely to have a history of exchanging sex for money or food. In addition, people who did not know their test results held more negative HIV testing attitudes and saw fewer benefits of testing than their counterparts who knew their test results. It is possible that some individuals who stated that they did not know their HIV status had left the testing site before notification of results. It is also possible that some individuals had been notified of their test results but did not understand the meaning of their HIV status. In either case, negative attitudes towards HIV testing may pose barriers to learning one's HIV test results.

HIV testing history was not associated with AIDS related knowledge, which was generally high in the current sample. Factual based education about HIV transmission is therefore once again found to be necessary but insufficient in promoting HIV antibody testing. ${ }^{12}$ In contrast, attitudes toward HIV testing were associated with testing history. Although people who had not been tested held more negative attitudes towards testing than those who had been tested, we still found that two thirds of untested people believed that testing helps them; more than half stated that testing helps prevent HIV, and more than half of people who had not been tested would like to know their HIV status. We therefore conclude that not seeking VCT is more a function of social barriers to getting tested, particularly AIDS stigmas, than a lack of perceived value of getting tested.

AIDS related stigmas create barriers to seeking VCT but not to learning one's test results. Participants in the current study who were not tested for HIV held significantly more AIDS related stigmatising beliefs than people who had been tested, including negative perceptions of people living with AIDS, a sense that people with AIDS should feel ashamed and guilty, and the endorsement of social sanctions for people living with AIDS. It is important to note that AIDS stigmas were also prevalent among people who had been tested for HIV, although to a lesser degree than among those who had not been tested. These findings are consistent with research in the United States which shows AIDS related stigmas promote and foster social isolation and discrimination against people with HIV-AIDS. ${ }^{10} 18$ Given the history of discrimination experienced by black South Africans, it is not surprising that they would avoid a medical test that potentially adds another source of stigma and discrimination even though apartheid (that is, legalised racial segregation) was abolished almost a decade ago.

Given the prevalence of AIDS stigmas in the black township in Cape Town as reported here, structural interventions are needed to change societal beliefs about people living with AIDS. The knowledge base of HIV prevention information is now high in South Africa, ${ }^{1}$ indicating that national efforts to educate the public about AIDS have been successful. However, knowledge appears to only be a necessary precursor to reducing stigma. In the United States, public health laws have been enacted to protect against AIDS discrimination and to protect the confidentiality of an individual's HIV status. ${ }^{19}$ Social marketing campaigns have been effective at raising AIDS awareness and reducing AIDS stigmas. ${ }^{20}$ Antistigma campaigns have also created positive environments for enacting policies to protect the human rights of people living with HIV-AIDS. ${ }^{21}$ Community mobilisation and social activism models can also have broad effects on AIDS stigmas.22 Efforts to reduce AIDS stigmas are already under way in South Africa through mass media campaigns and public demonstrations and should be sustained to ultimately achieve success. Only through these efforts will AIDS stigma in South Africa be reduced and the goals of VCT realised.

Results of the current study provide new information about factors that potentially influence HIV testing in South Africa. However, there are important limitations to the study that should be considered when interpreting these findings. The study reported here was conducted in one black township in Cape Town, South Africa. Although HIV prevalence in the Western Cape is nearly $11 \%$ it is relatively lower than four of the other eight South African provinces. ${ }^{1}$ Nearly all of the study participants were African and nearly all lived in poverty. Therefore, caution should be exercised before generalising the study results to other geographic regions and demographic groups. The study also relied on self report measures administered in public venues. Given the high degree of AIDS stigma in South Africa in general, it is likely that the already high rates of risk behaviours observed in the current study are underestimates of actual occurrences. In addition, the study design was cross sectional and therefore does not permit predictive, directional, or causal interpretations of the findings. The HIV testing and risk history measures did not include assessments of time since the behaviours occurred, not allowing us to examine whether people who were recently tested or who recently engaged in risk activities differed from those practising these behaviours less recently. Taking these methodological limitations into account, findings from the current study demonstrate an urgent need for anti-AIDS stigma campaigns and HIV prevention interventions in South Africa. Research is also needed to explore additional barriers to VCT uptake, including attributions of causes of HIV infection, the availability of HIV treatments, and beliefs about HIV treatments.

\section{Authors' affiliations \\ S C Kalichman, University of Connecticut, CT, USA L C Simbayi, Human Sciences Research Council, Cape Town, South Africa}

Funding: National Institute of Mental Health (NIMH) Grant R01MH61672 supported this research.

\section{REFERENCES}

1 Shinsasa O, Simbayi L. Nelson Mandela/HSRC study of HIV/AIDS: South African national HIV prevalence, behavioral risks and mass media, household survey 2002. Cape Town South Africa: Human Sciences Research Council, 2002.

2 World Health Organization/UNAIDS. AIDS epidemic update. Geneva: WHO, 2002. 
3 Kamb ML, Fishbein M, Douglas JM, et al and Project RESPECT Study Group. Efficacy of risk reduction counseling to prevent human immunodeficiency virus and sexually transmitted diseases. JAMA 1998;280:1161-7.

4 Voluntary HIV-1 Counseling and Testing Efficacy Study Group. Efficacy of voluntary HIV-1 counseling and testing in individuals and couples in Kenya, Tanzania, and Trinidad: A randomized trial. Lancet 2000;356:103-12.

5 Roffman RA, Kalichman S, Kelly JA, et al. HIV antibody testing of gay men in smaller cities. AIDS Care 1995;7:405-13.

6 Kalichman S, Rompa D, Muhammad A. Psychological predictors of risk for human immunodeficiency virus (HIV) infection among low-income inner-city men: a community-based survey. Psych Health 1996.

7 Chesney M, Smith A. Critical delays in testing and care: the potential role of stigma. Am Behav Scientist 1999;42:1162-74

8 Hull H, Bettinger C, Gallaher R. Comparison of HIV antibody prevalence in patients consenting to and declining HIV antibody testing in an STD clinic. JAMA 1988;260:935-8.

9 Stall R, Hoff C, Coates T, et al. Decisions to get HIV tested and to accept antiretroviral therapies among gay/bisexual men: implications for secondary prevention efforts. J AIDS 1996:11:151-60.

10 Herek GM, Capitanio JP, Widaman KF. Stigma, social risk, and health policy: public attitudes toward HIV surveillance policies and the social construction of illness. Health Psych (in press).

11 Van Dyk A. HIV/AIDS care and counseling: a multidisciplinary approach. South Africa: Pearson Education, 2001.

12 Fisher JD, Fisher WA. Changing AIDS-risk behavior. Psych Bull 1992;111:455-74.
13 Fullilove M, Fullilove R. Stigma as an obstacle to AIDS action. Am Behav Scientist 1999;42:1117-29.

14 Carey MP, Schroder KE. Development and psychometric evaluation of the brief HIV knowledge questionnaire (HIV-KQ-18). AIDS Ed Prev 2002; 14:174-84.

15 Herek GM, Capitanio JP, Widaman KF. HIV-related stigma and knowledge in the United States: prevalence and trends, 1991-1999. Am J Pub Health 2002;92:371-7.

16 Doll LS, Kennedy MB. HIV counseling and testing: what is it and how well does it work? In: Schochetman G, George JR, eds. AIDS testing: a comprehensive guide to technical, medical, social, legal and management issues. 2nd ed. New York: Springer-Verlag, 1994:302-19.

17 Ramanathan K, Tarantola D, Marlink R. Access to HIV and AIDS care. In: Essex M, Mboup S, Kanki P, Marlink R, Tlou S, eds. AIDS in Africa. Amsterdam: Kluwer Academic, 2002.

18 Herek GM, Glunt EK. An epidemic of stigma: public reactions to AIDS. Am Psych 1988;43:886-91.

19 Burris S. Studying the legal management of HIV-related stigma. Am Behav Scientist 1999;42:1229-44.

20 Blankenship K, Bray S, Merson M. Structural interventions in public health AIDS 2000;14:S11-21

21 Shriver M, Everett C, Morin S. Structural interventions to encourage primary HIV prevention among people living with HIV. AIDS 2000;14:S57-62.

22 Parker R, Aggleton P. HIV and AIDS-related stigma and discrimination: a conceptual framework and implications for action. Soc Sci Med 2003;57:13-24

\section{Clinical Evidence - Call for contributors}

Clinical Evidence is a regularly updated evidence based journal available worldwide both as a paper version and on the internet. Clinical Evidence needs to recruit a number of new contributors. Contributors are health care professionals or epidemiologists with experience in evidence based medicine and the ability to write in a concise and structured way.

\section{Currently, we are interested in finding contributors with an interest in the following clinical areas:}

Altitude sickness; Autism; Basal cell carcinoma; Breast feeding; Carbon monoxide poisoning; Cervical cancer; Cystic fibrosis; Ectopic pregnancy; Grief/bereavement; Halitosis; Hodgkins disease; Infectious mononucleosis (glandular fever); Kidney stones; Malignant melanoma (metastatic); Mesothelioma; Myeloma; Ovarian cyst; Pancreatitis (acute); Pancreatitis (chronic); Polymyalgia rheumatica; Post-partum haemorrhage; Pulmonary embolism; Recurrent miscarriage; Repetitive strain injury; Scoliosis; Seasonal affective disorder; Squint; Systemic lupus erythematosus; Testicular cancer; Varicocele; Viral meningitis; Vitiligo However, we are always looking for others, so do not let this list discourage you.

Being a contributor involves:

- Appraising the results of literature searches (performed by our Information Specialists) to identify high quality evidence for inclusion in the journal.

- Writing to a highly structured template (about 2000-3000 words), using evidence from selected studies, within 6-8 weeks of receiving the literature search results.

- Working with Clinical Evidence Editors to ensure that the text meets rigorous epidemiological and style standards.

- Updating the text every eight months to incorporate new evidence.

- Expanding the topic to include new questions once every 12-18 months.

If you would like to become a contributor for Clinical Evidence or require more information about what this involves please send your contact details and a copy of your CV, clearly stating the clinical area you are interested in, to Claire Folkes (cfolkes@bmigroup.com).

\section{Call for peer reviewers}

Clinical Evidence also needs to recruit a number of new peer reviewers specifically with an interest in the clinical areas stated above, and also others related to general practice. Peer reviewers are health care professionals or epidemiologists with experience in evidence based medicine. As a peer reviewer you would be asked for your views on the clinical relevance, validity, and accessibility of specific topics within the journal, and their usefulness to the intended audience (international generalists and health care professionals, possibly with limited statistical knowledge). Topics are usually 2000-3000 words in length and we would ask you to review between 2-5 topics per year. The peer review process takes place throughout the year, and our turnaround time for each review is ideally 10-14 days.

If you are interested in becoming a peer reviewer for Clinical Evidence, please complete the peer review questionnaire at www.clinicalevidence.com or contact Claire Folkes(cfolkes@bmigroup.com). 